\title{
Long-Term Safety Follow-Up of Subjects Previously Treated with Non-Replicating Retroviral Vector-Based Gene Therapies
}

\author{
Ramon Mohanlal $^{1} \cdot$ Yuhong Qiu $^{1} \cdot$ Ming Zheng $^{1} \cdot$ Asmae Mirkou $^{2}$ • \\ Kanaka Sridharan $^{3} \cdot$ Christopher Keir $^{3}$
}

Published online: 19 July 2016

(c) The Author(s) 2016. This article is published with open access at Springerlink.com

\begin{abstract}
Objective Our objective was to evaluate the life-long safety profile of gene therapy using retroviral (non-replicating) vectors (nRCR), or cell products in 127 subjects with hemophilia, human immunodeficiency virus (HIV), or cancer, previously treated with such gene therapy.

Methods We assessed the occurrence of serious adverse events (SAEs), deaths and presence of replication competent retrovirus (RCR).

Results A total of 23 subjects remained until the data cutoff date of 31 July 2013 and provided safety information of up to 18 years. Of the 104 subjects who discontinued, the primary reason was loss to follow-up $(47.2 \% ; n=60)$. The follow-up period for the 60 subjects lost to follow-up was 7-10 years. A total of 41 subjects experienced at least one SAE, and 15 subjects died. We reviewed SAEs and cause of death (none related to the active therapy), but no evidence was found for safety signals related to new malignancy or neurologic, rheumatological, autoimmune, or hematologic disorder. RCR results were negative, indicating no evidence for in vivo vector persistence.

Conclusion Despite the loss of follow-up, which is the limiting factor in this long-term safety trial, the findings from this long-term follow-up study are encouraging.
\end{abstract}

Christopher Keir

christopher.keir@novartis.com

1 Novartis Oncology, Novartis Pharmaceuticals Corporation, East Hanover, NJ, USA

2 Novartis Oncology, Novartis Pharma AG, Basel, Switzerland

3 Cell and Gene Therapies Unit, Novartis Pharmaceuticals Corporation, East Hanover, NJ, USA

\section{Key Points}

Following the report from a French study in patients with X-linked severe combined immunodeficiency (X-SCID), the clinical occurrence of malignancies due to insertional mutagenesis has raised concerns about the safety of gene therapy.

Advances in vector research, including the development of human immunodeficiency virus (HIV)-1-based lentivectors and new-generation retroviral (non-replicating) vectors, offer the hope of developing effective and safe gene therapy treatment.

This long-term follow-up study of up to 18 years in adult subjects treated with gene therapy using nonreplicating viral vectors showed no evidence of vector persistence or insertional mutagenesis related to gene therapy.

With renewed interest in the use of cell and gene therapies in a wide variety of debilitating conditions, the favorable long-term safety profile is highly encouraging.

\section{Introduction}

The principle of gene therapy is to achieve efficient delivery of the relevant genetic material into the target cell to express the transgene at therapeutic levels [1]. The first 
proof-of-principle gene transfer based on $\gamma$-retrovirus transduction was reported almost 20 years ago [2-5]. Early studies on gene therapy in patients with severe combined immunodeficiency (SCID) using $\gamma$-retroviral vectors showed improvement in disease condition with acceptable short-term safety profiles. However, these studies were conducted with an assumption that the potential for insertional activation of an oncogene or insertional inactivation of a tumor-suppression gene would be minimal $[6,7]$. This assumption was based on the evidence from early animal studies indicating minimal risk of tumor development with no reported incidence of vector-induced malignancy in mice and non-human primates [6]. Furthermore, two additional studies conducted in patients with X-linkedSCID in the early 2000s using a retroviral vector showed substantial improvement in clinical and pathological features of the disease condition with no insertional action on the oncogene or tumor suppressor gene [8, 9]. However, a study conducted in France wherein patients with X-SCID were transfused with ex vivo modified hematopoietic cells with a retroviral vector showed incidence of leukemia in 3 of 11 patients 30 months after gene therapy. This was believed to be caused by monoclonal $\mathrm{T}$ cell expansion and was determined to be related to the gene transfer product $[10,11]$. It was further observed that retroviral vector copies were present in the leukemia cells of the two patients with leukemia, which may have triggered cellular oncogene at the site of integration by a process known as 'insertional mutagenesis'. Hence, persistence of integrated vectors may have contributed to the development of leukemia [12].

Based on the findings from the French study in patients with X-SCID, the application of retroviral vectors was believed to be associated with potential risk factors, including (1) the formation of a replication competent retrovirus (RCR) as a result of recombination of retroviral vectors with genomes of the helper cells, infected cells, or another virus; (2) integration of retrovirus vector in the vicinity of a growth factor gene/proto-oncogene, leading to their activation, and increasing the probability of the development of cancer [13]. The risks associated with retroviral vector administration eclipsed the clinical benefit of gene therapy and discouraged their further development for almost two decades.

Advancements in vector research, including the development of human immunodeficiency virus (HIV)-1-based lentivectors and new-generation retroviral (non-replicating) vectors (nRCR) designed to reduce the potential of RCR, and targeted transduction, offered the hope of developing effective and safe gene therapy treatment [1, 14-16]. Gamma-retroviral vectors used for gene transfer into $\mathrm{T}$ cells have been reported to be safe; no adverse effects from insertional mutagenesis in any patient infused with $\mathrm{T}$ cells modified with these vectors have been reported [17]. However, subjects exposed to gene transfer technology may be at risk of delayed adverse events because of persistent biological activity of the genetic material; thus, long-term follow-up of subjects utilizing this vector is recommended as per the US FDA 2006 guidance [18].

Chiron Technologies previously conducted 11 studies using new-generation nRCR-based gene therapy in subjects with hemophilia (one study), HIV (six studies), and various malignancies (four studies, including metastatic melanoma, chronic myelogenous leukemia, chronic lymphocytic leukemia, multiple myeloma) (Table 1). Results from these studies showed improvement in disease condition with an acceptable short-term safety profile. However, available data on the long-term safety profile of nRCR are limited. The FDA has provided guidance [18] regarding the longterm follow-up of participants in gene therapy clinical research. Based on this guidance, integrating vectors (such as gamma-retrovirus) have the potential to initiate neoplastic processes depending upon the site of integration and the presence of strong promoter/enhancer elements present in the gene transfer vector. In addition, host characteristics, such as immune status of the recipient, route of administration, and type of cell targeted for transformation, contribute to long-term risk [19].

The objective of the current study was to evaluate the life-long safety profile of gene therapy using nRCR or cell products in subjects with hemophilia, HIV, or cancer who participated in the 11 studies conducted by Chiron Technologies.

\section{Methods}

\subsection{Study Design and Population}

This was a phase II follow-up study (follow-up start date: June 1998) investigating the long-term safety of subjects who previously received retroviral vectors or cell products (active therapy) in any one of 11 Chiron Technologies Center for Gene Therapy retrovirus treatment protocols. Table 1 provides details of the gene therapy, vectors used, and doses and duration of treatment for the enrolled subjects in each of these studies.

As per the present study protocol, subjects were to be followed-up annually for the duration of the subject's life or until the subject was lost to follow-up. Subjects did not receive any gene therapy during the present long-term follow-up study. Subjects who became pregnant during the follow-up study were allowed to continue in the study.

This study was conducted in accordance with the ethical principles of the Declaration of Helsinki and approved by the institutional review board or ethics committee at each 


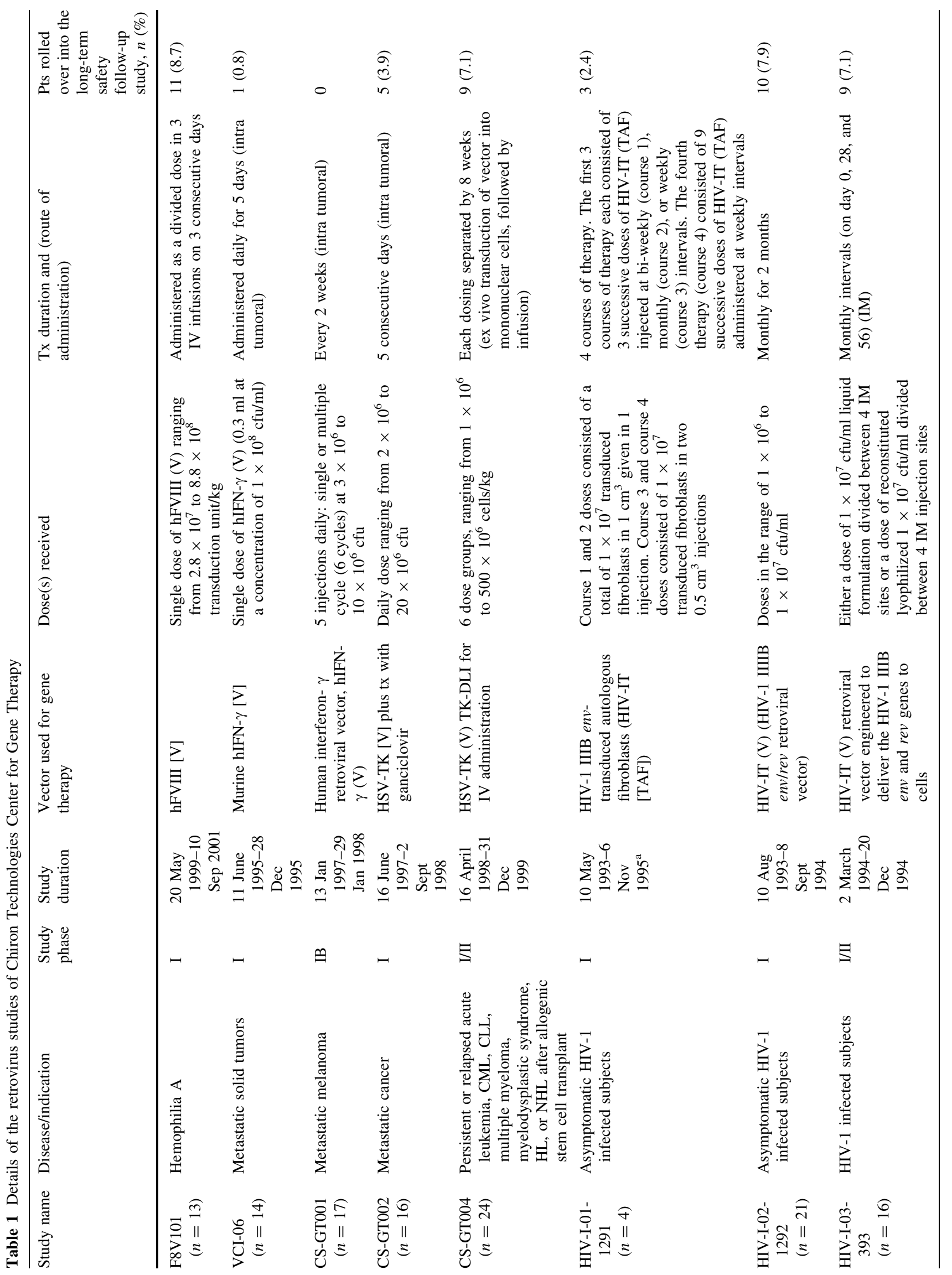




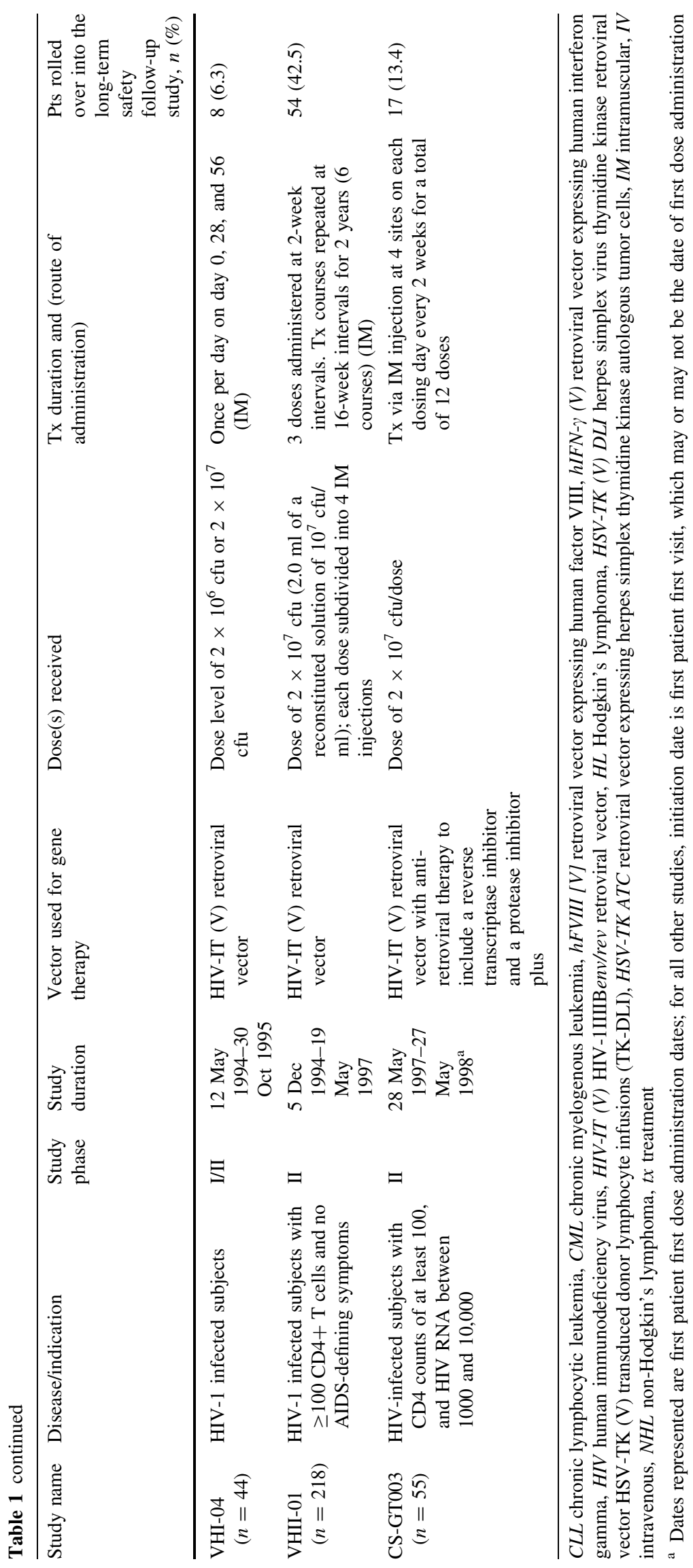


participating site. All subjects provided written informed consent before enrollment (protocol identification: Chiron Corporation protocol number CS-GT005/Novartis protocol number CRV789A2201).

\subsection{Safety Evaluations}

All serious adverse events (SAEs), including deaths, were reported. In addition, if an SAE was thought to be related to vector administration, RCRs were tested via polymerase chain reaction (PCR) and vector integration studies. Any unresolved SAEs or toxicities were followed until resolution or until they were determined to be chronic.

As per the 2006 FDA guidance for cell and gene therapies [18], the incidence of any new malignancy, new incidence or exacerbation of neurologic disorder, new incidence or exacerbation of rheumatologic or autoimmune disorder, or new incidence of hematologic disorder was considered an SAE of special interest in patients receiving gene therapies.

\subsection{Data Collection}

The incidence of SAEs was assessed at 1 year after the last retroviral vector administration and annually thereafter. In subjects who completed a 1-year follow-up period in the original gene therapy study prior to this follow-up study, the incidence of SAEs was assessed 2 years after the last dose of vector administration and annually thereafter.

\subsection{Blood Collection}

Blood samples for banking of peripheral blood mononuclear cells (PBMC) for RCR were collected annually for the duration of the life-long follow-up or until the subject was deemed lost to follow-up.

For subjects who participated in the vector integration studies, an additional blood sample was collected and stored every 6 months during the first 5 years after last retroviral vector administration and annually during years 6-10 to enable the analysis of clonality of vector integration sites, if required. In the event of death, an autopsy was conducted and tissue samples for RCR testing were collected depending on the cause of death and gross findings on autopsy.

For subjects for whom RCR testing was not performed in the respective treatment studies, testing for RCR was planned in the current study.

\subsection{Statistical Analysis}

We included safety data up to the cut-off date of 31 July 2013 in the analysis for this report. No formal statistical comparisons were planned for this study. The sample size was not based on statistical considerations. The analysis included all enrolled subjects who received active treatment in the previous gene therapy study. The data collected are summarized and presented by treatment indication: hemophilia A, cancer, or HIV.

\section{Results}

\subsection{Study Population}

The present study included 127 subjects who received active treatment and 52 subjects who received placebo. After a protocol amendment, follow-up of the 52 subjects who received placebo was stopped. On the data cut-off date of 31 July 2013, of the 127 subjects who previously received active treatment, 23 remained in the study and 104 had discontinued. The primary reason for discontinuation was loss to follow-up $(47.2 \% ; n=60$; all from the HIV group) (Fig. 1). A total of 15 subjects died during the follow-up study. Loss to follow-up typically occurred during years 7-10. The majority of subjects enrolled were from HIV studies $(79.5 \% ; n=101)$. Across all studies, the mean (standard deviation [SD]) age of subjects was 44 (11.0) years, and the majority were men $(81.9 \% ; n=104)$ and Caucasian ( $88.2 \% ; n=112$ ) (Table 2). None of the female subjects became pregnant during the follow-up. The median follow-up duration was 6.42 years, and 42 $(33.0 \%)$ subjects were followed for a minimum of 10 years. For subjects who received previous active therapy for hemophilia $(n=11)$, the mean (SD) follow-up duration was 9.39 (3.53) years (Table 3).

Of the 23 subjects who remained in the study (as of the data cut-off date), 14 had a safety follow-up between 12 and $<15$ years and nine subjects had a follow-up of at least 15 years.

\subsection{Safety Findings}

Overall, 41 subjects experienced at least one SAE (Table 4). The most frequently reported SAE was pneumonia $(5.5 \% ; n=7)$. None of the SAEs were considered by the investigator to be related to the active treatment received in the original study.

SAEs in the categories of special interest as per the FDA guidance were reported in 17 subjects who received previous active treatment and included malignancies $(n=12)$ and a neurologic disorder $(n=5)$. Three subjects with malignancies also reported other SAEs of special interest: rheumatologic or autoimmune disorder $(n=1)$ and hematologic disorder $(n=2)$. Of the 12 subjects who reported malignancies, 11 subjects died (see next 
Fig. 1 Subject disposition in the long-term safety follow-up study. Single asterisk subjects receiving placebo in the Chiron Technologies studies were not followed-up as per protocol amendment. Double asterisks subjects lost to follow-up were from HIV studies. Hash subjects who remained in the study at the data cut-off date of 31 July 2013. HIV human immunodeficiency virus
Table 2 Demographics of subjects enrolled in the longterm safety follow-up study

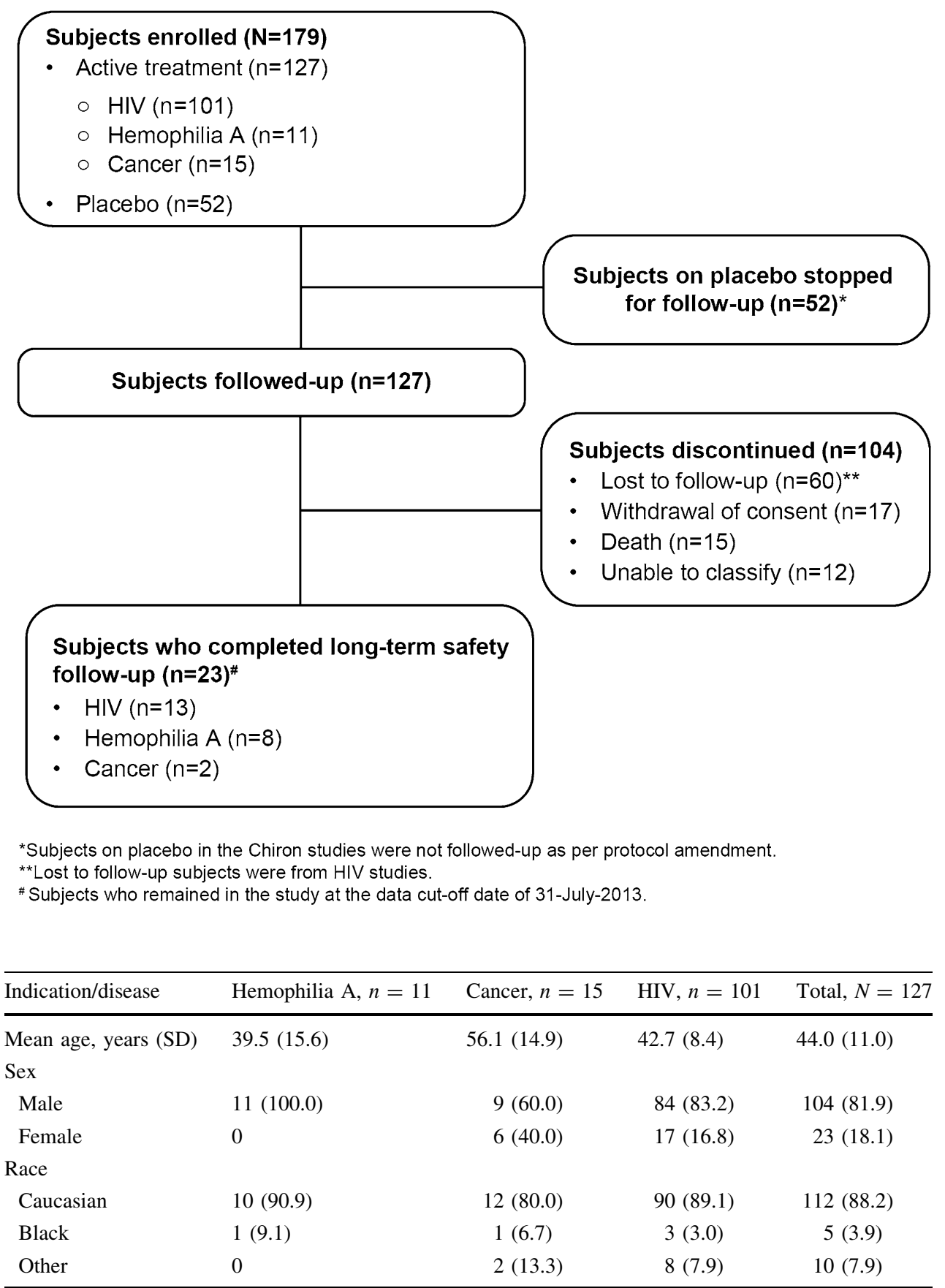

Data are presented as $n(\%)$ unless otherwise indicated

$H I V$ human immunodeficiency virus paragraph) and one subject experienced a non-fatal SAE. Table 5 presents detailed results for the SAEs of special interest. None of the SAEs of special interest were considered by the investigator to be related to the active therapy administered in the previous gene therapy studies.

Among the subjects who received active treatment in the previous studies, 15 deaths were reported until the data cutoff date. None of the deaths were considered by the investigator to be related to the active treatment administered in the previous gene therapy studies. Of the 11 deaths due to neoplasms, eight were due to progression of the underlying malignant disease that was the clinical indication for the initial gene therapy trial in subjects with malignancy (metastatic malignant melanoma $[n=3]$, chronic lymphocytic leukemia $[n=2]$, malignant melanoma $[n=1]$, metastatic neoplasm $[n=1]$, plasma cell 
Table 3 Study duration (all subjects)

\begin{tabular}{|c|c|c|c|c|}
\hline & Hemophilia A, $n=11$ & Oncology, $n=15$ & $\mathrm{HIV}, n=101$ & Total, $N=127$ \\
\hline \multicolumn{5}{|c|}{ Study duration, years } \\
\hline Mean (SD) & $9.4(3.5)$ & $5.5(4.8)$ & $7.1(4.9)$ & $7.1(4.9)$ \\
\hline Median & 10.8 & 4.3 & 6.3 & 6.4 \\
\hline Range & $2.01-11.98$ & $0.03-13.21$ & $0.59-15.11$ & $0.03-15.11$ \\
\hline \multicolumn{5}{|c|}{ Study duration, years, n (\%) } \\
\hline$<3$ & $1(9.1)$ & $6(40.0)$ & $27(26.7)$ & $34(26.8)$ \\
\hline 3 to $<6$ & $2(18.2)$ & $3(20.0)$ & $22(21.8)$ & $27(21.3)$ \\
\hline 6 to $<9$ & 0 & $1(6.7)$ & $17(16.8)$ & $18(14.2)$ \\
\hline 9 to $<10$ & 0 & $2(13.3)$ & $4(4.0)$ & $6(4.7)$ \\
\hline 10 to $<11$ & $3(27.3)$ & 0 & $4(4.0)$ & $7(5.5)$ \\
\hline 11 to $<12$ & $5(45.5)$ & 0 & $4(4.0)$ & $9(7.1)$ \\
\hline 12 to $<13$ & 0 & $1(6.7)$ & $3(3.0)$ & $4(3.1)$ \\
\hline$\geq 13$ & 0 & $2(13.3)$ & $20(19.8)$ & $22(17.3)$ \\
\hline
\end{tabular}

$H I V$ human immunodeficiency virus, $S D$ standard deviation

Table 4 Most frequently $(n \geq 2)$ reported serious adverse events during the long-term safety follow-up study

\begin{tabular}{|c|c|c|c|c|}
\hline Preferred term & Hemophilia, $n=11$ & Oncology, $n=15$ & HIV, $n=101$ & Total, $N=127$ \\
\hline Subjects with SAE(s) & 7 (63.6) & $11(73.3)$ & $23(22.8)$ & $41(32.3)$ \\
\hline Pneumonia & $1(9.1)$ & $3(20.0)$ & $3(3.0)$ & $7(5.5)$ \\
\hline Dehydration & 0 & 0 & $4(4.0)$ & $4(3.1)$ \\
\hline Appendicitis & 0 & 0 & $3(3.0)$ & $3(2.4)$ \\
\hline Metastatic malignant melanoma & 0 & $3(20.0)$ & 0 & $3(2.4)$ \\
\hline Deep vein thrombosis & 0 & $2(13.3)$ & $1(1.0)$ & $3(2.4)$ \\
\hline Diarrhea & 0 & 0 & $2(2.0)$ & $2(1.6)$ \\
\hline Sepsis & $1(9.1)$ & $1(6.7)$ & 0 & $2(1.6)$ \\
\hline Influenza & $1(9.1)$ & $1(6.7)$ & 0 & $2(1.6)$ \\
\hline Depression & 0 & 0 & $2(2.0)$ & $2(1.6)$ \\
\hline Suicide attempt & 0 & 0 & $2(2.0)$ & $2(1.6)$ \\
\hline Myocardial infarction & 0 & $1(6.7)$ & $1(1.0)$ & $2(1.6)$ \\
\hline
\end{tabular}

Data are presented as $n(\%)$

$H I V$ human immunodeficiency virus, SAE serious adverse event

myeloma $[n=1])$. In one subject with underlying metastatic malignant melanoma, death was due to development of metastatic pancreatic carcinoma that was diagnosed 8.5 years after the last dose of study drug in the previous gene therapy study CS-GT004. In two other cases, one death was due to new malignancies that developed in subjects with HIV-Kaposi's sarcoma, and the other death was due to malignant lung neoplasm (Table 5). The subject who died because of Kaposi's sarcoma did so 3.26 years after the last dose of gene therapy administered in the previous study (VHII-01) for the treatment of HIV. Kaposi's sarcoma was confirmed by the examination of lesions on the subject's skin. Likewise, the subject with malignant lung neoplasm had a history of tobacco use and died 5 years after the last retroviral vector administration in the previous study (HIV-03-393) for the treatment of HIV.
Two neurological disorders led to deaths: encephalopathy $(n=1)$ in a subject with HIV, and intracranial hemorrhage $(n=1)$ in a subject with hemophilia.

The remaining two deaths occurred outside the SAEs of special interest: cardiac arrest $(n=1)$ and suicide $(n=1)$.

In the initial active-treatment study, RCR data were obtained from 127 subjects. All RCR results obtained in the initial studies were negative, except a transient positive test in the seminal fluid of one subject from the hemophilia study. This subject had a single transiently positive PCR test for the retroviral vector in his semen on day 55. Repeat tests on days $75,82,96$, and 110 were negative. Of note, this subject participated in the current follow-up study and had not experienced any SAEs up to the data cut-off date of 31 July 2013. None of the SAEs reported in this long-term 
Table 5 Incidence of serious adverse events of special interest (as defined by the US FDA for cell and gene therapies) reported during the longterm safety follow-up study

\begin{tabular}{|c|c|c|c|c|}
\hline Incidence of SAEs of special interest (SOC $/$ preferred term) & $\begin{array}{l}\text { Hemophilia, } \\
n=11\end{array}$ & $\begin{array}{l}\text { Oncology, } \\
n=15\end{array}$ & $\begin{array}{l}\text { HIV, } \\
n=101\end{array}$ & $\begin{array}{l}\text { Total, } \\
N=127^{\mathrm{b}}\end{array}$ \\
\hline $\begin{array}{l}\text { Neoplasms benign, malignant and unspecified (including cysts and } \\
\text { polyps) }\end{array}$ & 0 & $8(53.3)$ & $3(3.0)$ & $11(8.7)$ \\
\hline Metastatic malignant melanoma $^{\mathrm{c}}$ & 0 & $3(20.0)$ & 0 & $3(2.4)$ \\
\hline Chronic lymphocytic leukaemia ${ }^{\mathrm{c}, \mathrm{d}}$ & 0 & $1(6.7)$ & 0 & $1(0.8)$ \\
\hline Kaposi's sarcoma ${ }^{c}$ & 0 & 0 & $1(1.0)$ & $1(0.8)$ \\
\hline Lung neoplasm malignant ${ }^{\mathrm{c}}$ & 0 & 0 & $1(1.0)$ & $1(0.8)$ \\
\hline Malignant melanoma ${ }^{c}$ & 0 & $1(6.7)$ & 0 & $1(0.8)$ \\
\hline Metastases to lung & 0 & 0 & $1(1.0)$ & $1(0.8)$ \\
\hline Metastatic neoplasm $^{\mathrm{c}}$ & 0 & $1(6.7)$ & 0 & $1(0.8)$ \\
\hline Pancreatic carcinoma ${ }^{\mathrm{c}}$ & 0 & $1(6.7)$ & 0 & $1(0.8)$ \\
\hline Plasma cell myeloma $^{c}$ & 0 & $1(6.7)$ & 0 & $1(0.8)$ \\
\hline Renal cell carcinoma & 0 & 0 & $1(1.0)$ & $1(0.8)$ \\
\hline Nervous system disorders & $2(18.2)$ & 0 & $2(2.0)$ & $4(3.1)$ \\
\hline Carotid artery stenosis & $1(9.1)$ & 0 & 0 & $1(0.8)$ \\
\hline Haemorrhage intracranial ${ }^{\mathrm{c}, \mathrm{e}}$ & $1(9.1)$ & 0 & 0 & $1(0.8)$ \\
\hline Neuralgia & 0 & 0 & $1(1.0)$ & $1(0.8)$ \\
\hline Neuropathy peripheral & 0 & 0 & $1(1.0)$ & $1(0.8)$ \\
\hline Syncope & 0 & 0 & $1(1.0)$ & $1(0.8)$ \\
\hline Immune system disorders & 0 & $1(6.7)$ & 0 & $1(0.8)$ \\
\hline Drug hypersensitivity & 0 & $1(6.7)$ & 0 & $1(0.8)$ \\
\hline Blood and lymphatic system disorders & 0 & $2(13.3)$ & 0 & $2(1.6)$ \\
\hline Febrile neutropenia & 0 & $1(6.7)$ & 0 & $1(0.8)$ \\
\hline Pancytopenia & 0 & $1(6.7)$ & 0 & $1(0.8)$ \\
\hline
\end{tabular}

Data are presented as $n(\%)$

CLL chronic lymphocytic leukemia, HIV human immunodeficiency virus, SAEs serious adverse events

${ }^{a}$ This classification of the events was based on primary System Organ Class from the Medical Dictionary for Regulatory Activities

${ }^{b}$ In this table, one subject may have experienced more than one event. This table was generated automatically from the clinical database

c These SAEs of special interest resulted in death in 13 cases

d An additional subject who died from CLL is not reflected in this table as this single death was documented from another source and is therefore included in the text only (total CLL, $n=2$ )

e An additional subject who died from encephalopathy is not reflected in this table as this single death was documented from another source and is therefore included in the text only

safety protocol were considered to be related to the study drug; therefore, no DNA samples were required to be analyzed by PCR for RCR as per the protocol. However, testing was performed in 20 subjects who entered in the present long-term safety study without completing the first year follow-up of the active treatment study; the results were negative for RCR.

\section{Discussion}

This study evaluated the long-term safety and evidence of vector persistence in subjects who were followed for up to 18 years after treatment with nRCRs or ex vivo retroviral vector gene-transduced cell products. With a renewed interest in the use of cell and gene therapies in a wide variety of debilitating conditions [20], the long-term safety findings reported here are of paramount importance and highly encouraging. The negative RCR findings in the present study suggests lack of in vivo vector persistence during the long-term follow-up. In addition, investigators deemed the SAEs, including death, reported in this study not related to the active gene therapy. Although the findings cannot be generalized to conclude that all gene therapies are safe, this study is one of the early reports to provide insight into the long-term safety of gene-transduced cell products.

Two major safety concerns with use of retroviral vectors include the risk of insertional mutagenesis with increased 
probability of subsequent malignancy and the possibility of generating RCR [16]. Following the report from the French study on the development of new malignancy in three children with X-SCID after exposure to a retroviral vector $[10,11]$, the FDA provided specific recommendations on the long-term monitoring of patients participating in studies utilizing products derived from either gamma-retroviruses or lentiviruses [21]. The SAEs of special interest as outlined in the FDA guidance include new malignancies, new incidence or exacerbation of neurologic disorder, new incidence or exacerbation of rheumatologic or autoimmune disorder, and new incidence of hematologic disorder [18].

The present study found no indication of emergence of any new safety signals of neurologic disorders, rheumatological or autoimmune disorders, or hematologic disorders. Development of new malignancies was identified in four subjects; three were fatal and one was non-fatal. Two of the three fatal cases were in subjects who received gene therapy for the treatment of HIV. In one case, the patient developed Kaposi's sarcoma, which was diagnosed 20 months after the last dose of active treatment. In the second HIV patient, malignant lung neoplasm was diagnosed 5 years after the last dose of active treatment. The third fatal case was a subject who was treated with gene therapy for multiple myeloma and developed metastatic pancreatic carcinoma 8.5 years after the last dose of active treatment. The non-fatal case was in a HIV patient who developed renal cell carcinoma and metastases to the lung, both of which were diagnosed 3 years after the last dose of active therapy. The investigator did not consider any of these events to be related to the previous study treatment. Assessment of these critically ill subjects is particularly difficult because of complications from the underlying disease. Three of these four subjects had confounding factors relating to the complications of the underlying disease. For example, Kaposi's sarcoma is predominantly associated with HIV [22], and the patient who developed a malignant lung neoplasm had a history of tobacco use. Likewise, renal cell carcinoma is also associated with HIV [23].

Moloney murine leukemia retrovirus (MLV-RV) containing the corrective gene $\gamma_{c}$ utilized in the X-SCID trial raised some concerns related to genotoxic risk associated with uncontrolled insertion into the genome of CD34 + hematopoietic stem/progenitor cells [10]. Uncontrolled insertion of the retrovirus resulted in the copy of the vector DNA found in the growth-promoting gene or near the proto-oncogene, i.e., genes known to regulate stem-cell proliferation. This resulted in T-cell leukemia in the X-SCID patients between 3 and 6 years after gene therapy $[10,16]$. As with the X-SCID trial, insertional oncogenesis was also reported in early trials in patients with Wiskott Aldrich syndrome (WAS) and chronic granulomatous disease (CGD) using retroviral vector [24-26]. However, such adverse events were not reported with MLV-RV used to treat adenosine deaminase (ADA)SCID [27]. Analysis of the mechanisms of retroviral integration and mutagenesis suggest that the likelihood of mutagenesis may be affected by other factors, such as underlying disease, cell type, and transgene or specific vector and transduction characteristics [8, 11, 28]. Moreover, the authors of the WAS trial opined that the relatively high vector copy number per cell, in addition to the disease background, may have contributed to the increased risk of insertional mutagenesis [24]. These findings prompted the development of safer vector constructs based on self-inactivating (SIN) retroviral or lentiviral vectors (LVs) [29].

The retroviral vectors used in the 11 Chiron studies lacked the coding sequences to generate replication while retaining the elements required for efficient reverse transcription, integration, or transcription in the transduced host cell. In addition, Southern blot analysis of human genomic DNA failed to demonstrate any significant homology with Moloney virus. Also, unlike X-SCID [6]—which is a single inherited gene disorder (mutation of $\gamma_{c}$-encoding gene) occurring in infants/young children where retroviral vectors were used for the integration of the functional copy of $\gamma_{c}$ gene into the genome of CD34+ hematopoietic stem/progenitor cells [30] - the Chiron gene therapy products were used in adults for the treatment of HIV, cancer, or hemophilia (11 studies). Furthermore, the gene therapies were either injected directly into the tumor, administered as intramuscular or intravenous injections, or used to transfect PBMCs that were non-stem cell in origin. With direct intratumor, intramuscular, or intravenous injection, no selective transduction of hematopoietic cells is possible, thus lowering the probability of stem- cell transfection. Likewise, production of renewable cell populations with ex vivo transfection of PBMCs is highly unlikely because (1) nonmobilized PBMCs contain very few stem cells; (2) the cell expansion using anti-CD3 antibody is very specific to the $\mathrm{T}$ cells and does not affect stem cells, and (3) mature T cells have limited potential for division and disappear over time. Thus, the lack of oncogenic effect in our study may be attributed to the differences in the patients treated, age of patients, cell type (non-stem cell), vector (different from Moloney virus), or transduction characteristics compared with the X-SCID trial.

RCR could conceivably be produced by recombination in vivo. However, given the product characteristics of the Chiron gene therapies-i.e., lacking the coding sequences to replicate and the very low probability of stem cell transduction - the duration of in vivo vector persistence can be expected to be relatively short. Indeed, both in the active treatment study prior to long-term follow-up (in 127 subjects) and in the long-term follow-up study (in 20 
subjects), the RCR results were negative. The favorable safety profile and the absence of RCR in the current study further support the short vector persistence.

Our study had several limitations. The original study trials using gene therapy were conducted in a heterogeneous population of adults with HIV, cancer, or hemophilia. These disorders in themselves are a major confounding issue in identifying the cause of adverse events or any subsequent mortality. The sample size in this study was not based on any statistical considerations: all patients receiving active therapy in any of the 11 active treatment Chiron Technologies studies were enrolled in the long-term follow-up study. Although 127 subjects who received gene therapy were enrolled in the long-term follow-up study in June 1998, at the time of data cut-off in July 2013, only 23 subjects remained in the study. The remaining 104 subjects had discontinued, including 60 subjects who were lost to follow-up. Thus, the number of subjects under observation at the end of the 18-year follow-up interval is likely to be too small to allow definite conclusions on the long-term safety of the viral vector. Moreover, although we studied vector persistence by RCR, we did not study persistence of the transduced cells or conduct any karyotype assessment (beyond RCR) during the long-term follow-up, which further limits any definite conclusions on long-term safety. The author of a recent review on progress in gene therapy highlighted data from several clinical trials on gene therapies conducted in infants/children or adults in various indications that used lentiviral, gamma-retroviral, or adenoassociated virus as vectors for transduction [31]. Among the studies listed, very few had at least 3-year follow-up data, and only one study had data for up to 8 years of follow-up. The author contends that, in any given trial, the actual risk of genotoxicity is difficult to establish because of the low number of patients treated, the longer follow-up period needed, and possibility of the disease itself increasing the risk [31]. The findings of the present study cannot be generalized to all gene therapies utilizing retroviral vectors. A high number of patients were lost to follow-up in our study. Nevertheless, the follow-up period for the 60 subjects lost to follow-up was between 7 and 10 years, and annual examinations in these subjects up to 5 years [21] did not show any adverse outcomes related to retroviral-based gene therapy, suggesting a lack of in vivo viral persistence in these subjects.

\section{Future Implications}

Over the past decade, efforts to ensure development of a safer vector system with a reduced potential for insertional mutagenesis have led to the development of SIN gammaretroviral vector [32-35]. Moreover, no recorded cases of insertional mutagenesis have been reported in studies that utilized retroviral gene transduction in subjects with HIV [36].

Developments in vector systems have also led to the introduction of lentiviruses that are potent and versatile vectors for ex vivo or in vivo gene transfer into dividing and non-dividing cells [37]. Lentivirus also belong to the retrovirus family; however, several changes have been made to their genome to maximize safety and minimize the risk of generating replication-competent wild-type HIV-1 recombinants $[37,38]$. Separation of the transducing vector from the packaging plasmids in the HIV-1-based lentivirus decreases the generation of replication-competent lentivirus (RCL) [37, 39]. These improvements in molecular constructs for LV generation mean the probability of RCL recombinants is extremely low [40]. To our knowledge, no such cases have yet been reported [41]. Moreover, lentiviruses differ in their integration profile from gammaretroviruses, and the absence of a long-terminal repeat promotor in the integrated pro-virus of modern-generation SIN lentiviruses make them less genotoxic [39]. In a phase I open-label nonrandomized controlled trial for HIV utilizing LVs for gene transduction, no evidence for insertional mutagenesis was reported after 21-36 months of observation [42].

The ability of LVs to transduce non-dividing cells means they have a wide variety of applications that are undergoing clinical testing in many genetic disorders. These include the treatment of beta-thalassemia, adrenoleukodystrophy, Parkinson's disease, WiskottAldrich syndrome, acquired immunodeficiency syndrome, and cancer [37, 38]. One such advance in cancer therapy is the use of genetically modified $\mathrm{T}$ cells via LVs or retroviral vectors for ex vivo transduction of patient $\mathrm{T}$ cells with chimeric antigen receptor (CAR) sequence to stably express a fragment of an antibody on their surface, conferring new antigen specificity to target several malignancies [38]. CD19 is one such target expressed on most B-cell malignancies, and CAR therapies targeting CD19-specific malignancies have reported high response rates in hematological malignancies such as acute lymphoblastic leukemia (ALL) [43].

CTL019 is a CAR T therapy of autologous T cells genetically modified to target CD19 through transduction with an LV expressing anti-CD19 linked to CD3-zeta and CD137 (4-1BB) signaling domains [43, 44]. In patients with relapsed or refractory ALL, CTL019 was associated with a high remission rate $(90 \%)$ - even among patients for whom stem-cell transplantation had failed-and durable remissions up to 24 months were observed [45]. The probability of persistence of CTL019 was $68 \%$ at 6 months. Prolonged persistence for as long as 2 years in patients with ALL and as long as 3 years in patients with 
chronic lymphocytic leukemia (CLL) has been reported [45, 46]. This persistence of CTL019 is thought to provide a continued clinical benefit. Current safety data in patients monitored in these studies (up to 24 months) have not reported any concerns on insertional mutagenesis [44, 45].

For any gene therapy with persistent biological activity, the potential for delayed adverse events is currently considered high [21]. LVs, as with gamma-retrovirus and herpesvirus, are considered to pose a high risk of delayed adverse events, and the FDA recommends long-term follow-up observational studies to mitigate any potential longterm risks to subjects receiving these vectors $[18,21,40]$. Based on the FDA guidance, long-term follow-up observational studies for up to 15 years are planned for all CTL019 studies.

\section{Conclusions}

Follow-up of all subjects in the Chiron Technologies studies who received gene therapies using non-replicating gamma-retroviral vectors for transduction for at least 7 years, with 12-18 years of long-term safety data available for one-fifth of these subjects, found no evidence of vector persistence or insertional mutagenesis related to gene therapy. Although the findings cannot be generalized to conclude that all gene therapies are safe, this study is one of the early reports to provide insight into the long-term safety of gene-transduced cell products. With the renewed interest in the use of cell and gene therapies in a wide variety of debilitating conditions, the favorable long-term safety profile is highly encouraging. CTL019, a CAR T therapy, is a genetically modified T-cell therapy targeting CD19 that utilizes LVs for transduction. Safety data for up to 2 years in patients using CTL019 have not indicated any concerns with the use of LVs, and long-term follow-up observational studies for up to 15 years are planned for all CTL019 studies.

Acknowledgments The authors acknowledge the support of all participating investigators. The authors wish to thank Linda Armstrong, MD, Chief Medical Officer, Novartis Cell \& Gene Therapies Unit, for valuable input. The authors also wish to thank Dinesh T. Makhija (DM) from Novartis Healthcare Pvt. Ltd, Hyderabad, India, for providing editorial support of the manuscript. Based on input and guidance from all authors, the introduction, methods and results were drafted by DM and the discussion was drafted by KS with guidance from CK and RM. All authors reviewed the draft and provided critical comments, and the final submitted version has been approved by all authors.

\section{Compliance with Ethical Standards}

Conflict of interest and disclosures Yuhong Qiu (YQ), Ming Zheng (MZ), Asmae Mirkou (AM), Kanaka Sridharan (KS), and Christopher Keir (CK) are employees of Novartis. At the time the study was conducted and during development of the publication, Ramon Mohanlal (RM) was an employee at Novartis. Currently, RM is an independent consultant.

Funding The study was supported by Novartis Oncology.

Ethical approval and informed consent This study was conducted in accordance with the ethical principles of the Declaration of Helsinki and approved by the institutional review board or ethics committee at each participating site. All subjects provided written informed consent before enrolment (Protocol identification: Chiron Corporation protocol number CS-GT005/Novartis protocol number CRV789A2201).

Open Access This article is distributed under the terms of the Creative Commons Attribution-NonCommercial 4.0 International License (http://creativecommons.org/licenses/by-nc/4.0/), which permits any noncommercial use, distribution, and reproduction in any medium, provided you give appropriate credit to the original author(s) and the source, provide a link to the Creative Commons license, and indicate if changes were made.

\section{References}

1. Escors D, Breckpot K. Lentiviral vectors in gene therapy: their current status and future potential. Arch Immunol Ther Exp. 2010;58:107-19.

2. Brenner MK, Rill DR, Holladay MS, Heslop HE, Moen RC, Buschle M, et al. Gene marking to determine whether autologous marrow infusion restores long-term haemopoiesis in cancer patients. Lancet. 1993;342:1134-7.

3. Deisseroth AB, Zu ZF, Claxton D, Hanania EG, Fu SQ, Ellerson $\mathrm{D}$, et al. Genetic marking shows that $\mathrm{Ph}(+)$ cells present in autologous transplants of chronic myelogenous leukemia $(\mathrm{Cml})$ contribute to relapse after autologous bone-marrow in $\mathrm{Cml}$. Blood. 1994;83:3068-76.

4. Dunbar CE, Cottler-Fox M, O'Shaughnessy JA, Doren S, Carter $\mathrm{C}$, Berenson R, et al. Retrovirally marked CD34-enriched peripheral blood and bone marrow cells contribute to long-term engraftment after autologous transplantation. Blood. 1995;85:3048-57.

5. Rill DR, Santana VM, Roberts WM, Nilson T, Bowman LC, Krance RA, et al. Direct demonstration that autologous bonemarrow transplantation for solid tumors can return a multiplicity of tumorigenic cells. Blood. 1994;84:380-3.

6. Anderson WF, Blaese RM, Culver K. The ADA human gene therapy clinical protocol: points to consider response with clinical protocol, July 6, 1990. Hum Gene Ther. 1990;1:331-62.

7. Blaese RM, Culver KW, Chang L, Anderson WF, Mullen C, Nienhuis A, et al. Treatment of severe combined immunodeficiency disease (SCID) due to adenosine-deaminase deficiency with $\mathrm{Cd} 34+$ selected autologous peripheral-blood cells transduced with a human Ada gene. Hum Gene Ther. 1993;4:521-7.

8. Cavazzana-Calvo M, Hacein-Bey S, de Saint Basile G, Gross F, Yvon E, Nusbaum P, et al. Gene therapy of human severe combined immunodeficiency (SCID)-X1 disease. Science. 2000;288:669-72.

9. Gaspar HB, Parsley KL, Howe S, King D, Gilmour KC, Sinclair $\mathrm{J}$, et al. Gene therapy of X-linked severe combined immunodeficiency by use of a pseudotyped gammaretroviral vector. Lancet. 2004;364:2181-7.

10. Hacein-Bey-Abina S, Von Kalle C, Schmidt M, McCormack MP, Wulffraat N, Leboulch $\mathrm{P}$, et al. LMO2-associated clonal T cell proliferation in two patients after gene therapy for SCID-X1. Science. 2003;302:415-9. 
11. Couzin J, Kaiser J. Gene therapy-as Gelsinger case ends, gene therapy suffers another blow. Science. 2005;307:1028.

12. Kohn DB, Sadelain M, Glorioso JC. Occurrence of leukaemia following gene therapy of X-linked SCID. Nat Rev Cancer. 2003;3:477-88.

13. Anson DS. The use of retroviral vectors for gene therapy-what are the risks? A review of retroviral pathogenesis and its relevance to retroviral vector-mediated gene delivery. Genet Vaccines Ther. 2004;2:9.

14. Hematti P, Hong BK, Ferguson C, Adler R, Hanawa H, Sellers S, et al. Distinct genomic integration of MLV and SIV vectors in primate hematopoietic stem and progenitor cells. PLoS Biol. 2004;2:e423.

15. Yi Y, Hahm SH, Lee KH. Retroviral gene therapy: safety issues and possible solutions. Curr Gene Ther. 2005;5:25-35.

16. Yi Y, Noh MJ, Lee KH. Current advances in retroviral gene therapy. Curr Gene Ther. 2011;11:218-28.

17. Huye LE, Dotti G. Designing T cells for cancer immunotherapy. Discov Med. 2010;9:297-303.

18. The US FDA guidance for industry: gene therapy clinical trialsobserving subjects for delayed adverse effects. 2006. http://www. fda.gov/downloads/BiologicsBloodVaccines/GuidanceCompliance RegulatoryInformation/Guidances/CellularandGeneTherapy/ucm 078719.pdf. Accessed 12 April 2016.

19. Long term follow-up of gene transfer patients. 2001. http://www. fda.gov/ohrms/dockets/ac/01/briefing/3794b1_01.htm. Accessed 12 April 2016.

20. Sheridan C. Gene therapy finds its niche. Nat Biotechnol. 2011;29:121-8.

21. The US FDA consideration for the design of early-phase clinical trials of cell and gene therapy products; guidance for industry. June 2015. http://www.fda.gov/downloads/Biologi/UCM359073. pdf. Accessed 12 April 2016.

22. Bhutani M, Polizzotto MN, Uldrick TS, Yarchoan R. Kaposi sarcoma-associated herpesvirus-associated malignancies: epidemiology, pathogenesis, and advances in treatment. Semin Oncol. 2015;42:223-46.

23. Gaughan EM, Dezube BJ, Aboulafia D, Bower M, Stebbing J, Powles $\mathrm{T}$, et al. Human immunodeficiency virus-associated renal cell carcinoma: a transatlantic case series. Clin Genitourin Cancer. 2008;6:86-90.

24. Braun CJ, Boztug K, Paruzynski A, Witzel M, Schwarzer A, Rothe M, et al. Gene therapy for Wiskott-Aldrich syndromelong-term efficacy and genotoxicity. Sci Transl Med. 2014;6:227ra33.

25. Siler U, Paruzynski A, Holtgreve-Grez H, Kuzmenko E, Koehl U, Renner ED, et al. Successful combination of sequential gene therapy and rescue Allo-HSCT in two children with X-CGD Importance of timing. Curr Gene Ther. 2015;15:416-27.

26. Ott MG, Schmidt M, Schwarzwaelder K, Stein S, Siler U, Koehl $\mathrm{U}$, et al. Correction of X-linked chronic granulomatous disease by gene therapy, augmented by insertional activation of MDS1EVI1, PRDM16 or SETBP1. Nat Med. 2006;12:401-9.

27. Aiuti A, Brigida I, Ferrua F, Cappelli B, Chiesa R, Marktel S, et al. Hematopoietic stem cell gene therapy for adenosine deaminase deficient-SCID. Immunol Res. 2009;44:150-9.

28. Cavazza A, Moiani A, Mavilio F. Mechanisms of retroviral integration and mutagenesis. Hum Gene Ther. 2013;24:119-31.

29. Cicalese MP, Aiuti A. Clinical applications of gene therapy for primary immunodeficiencies. Hum Gene Ther. 2015;26:210-9.

30. Cavazzana M, Six E, Lagresle-Peyrou C, Andre-Schmutz I, Hacein-Bey-Abina S. Gene therapy for X-linked severe combined immunodeficiency: where do we stand? Hum Gene Ther. 2016;27:108-16.

31. Naldini L. Gene therapy returns to centre stage. Nature. 2015;526:351-60.

32. Thornhill SI, Schambach A, Howe SJ, Ulaganathan M, Grassman E, Williams D, et al. Self-inactivating gammaretroviral vectors for gene therapy of X-linked severe combined immunodeficiency. Mol Ther. 2008;16:590-8.

33. Roesler J, Brenner S, Bukovsky AA, Whiting-Theobald N, Dull $\mathrm{T}$, Kelly M, et al. Third-generation, self-inactivating gp91(phox) lentivector corrects the oxidase defect in NOD/SCID mouse-repopulating peripheral blood-mobilized $\mathrm{CD} 34+$ cells from patients with $\mathrm{X}$-linked chronic granulomatous disease. Blood. 2002;100:4381-90.

34. Schwickerath O, Brouns G, Thrasher A, Kinnon C, Roes J, Casimir C. Enhancer-deleted retroviral vectors restore high levels of superoxide generation in a mouse model of CGD. J Gene Med. 2004;6:603-15.

35. Yu SF, Vonruden T, Kantoff PW, Garber C, Seiberg M, Ruther $\mathrm{U}$, et al. Self-inactivating retroviral vectors designed for transfer of whole genes into mammalian-cells. Proc Natl Acad Sci USA. 1986;83:3194-8.

36. Scholler J, Brady TL, Binder-Scholl G, Hwang WT, Plesa G, Hege KM, et al. Decade-long safety and function of retroviralmodified chimeric antigen receptor $\mathrm{T}$ cells. Sci Transl Med. 2012;4:132-53.

37. Matrai J, Chuah MK, VandenDriessche T. Recent advances in lentiviral vector development and applications. Mol Ther. 2010;18:477-90.

38. Oldham RA, Berinstein EM, Medin JA. Lentiviral vectors in cancer immunotherapy. Immunotherapy. 2015;7:271-84.

39. Dropulic B. Lentiviral vectors: their molecular design, safety, and use in laboratory and preclinical research. Hum Gene Ther. 2011;22:649-57.

40. Briefing document- testing for replication competent retrovirus (RCR)/lentivirus (RCL) in retroviral and lentiviral vector based gene therapy products - revisiting current FDA recommendations. http:// www.fda.gov/downloads/AdvisoryCommittees/CommitteesMeeting Materials/BloodVaccinesandOtherBiologics/CellularTissueandGene TherapiesAdvisoryCommittee/UCM232592.pdf. Accessed 12 April 2016.

41. Cornetta K, Yao J, Jasti A, Koop S, Douglas M, Hsu D, et al. Replication-competent lentivirus analysis of clinical grade vector products. Mol Ther. 2011;19:557-66.

42. Levine BL, Humeau LM, Boyer J, MacGregor RR, Rebello T, Lu $\mathrm{XB}$, et al. Gene transfer in humans using a conditionally replicating lentiviral vector. Proc Natl Acad Sci USA. 2006;103:17372-7.

43. Ghorashian S, Pule M, Amrolia P. CD19 chimeric antigen receptor $\mathrm{T}$ cell therapy for haematological malignancies. $\mathrm{Br} \mathrm{J}$ Haematol. 2015;169:463-78.

44. Kalos M, Levine BL, Porter DL, Katz S, Grupp SA, Bagg A, et al. $T$ cells with chimeric antigen receptors have potent antitumor effects and can establish memory in patients with advanced leukemia. Sci Transl Med. 2011;3:95ra73.

45. Maude SL, Frey N, Shaw PA, Aplenc R, Barrett DM, Bunin NJ, et al. Chimeric antigen receptor $\mathrm{T}$ cells for sustained remissions in leukemia. N Engl J Med. 2014;371:1507-17.

46. Porter DL, Hwang WT, Frey NV, Lacey SF, Shaw PA, Loren $\mathrm{AW}$, et al. Chimeric antigen receptor $\mathrm{T}$ cells persist and induce sustained remissions in relapsed refractory chronic lymphocytic leukemia. Sci Transl Med. 2015;7:303ra139. 